\title{
Aqueous-ozone irrigation of bone monocortical wounds in hyperglycemic rats ${ }^{1}$
}

\author{
Alexandre Viana Frascino ${ }^{I}$, Andrea Mantesso" ${ }^{\text {II }}$ Luciana Corrêa ${ }^{I I I}$, Maria Cristina Zindel Deboni ${ }^{\text {IV }}$ \\ IFellow PhD degree, Oral Pathology, Oral Pathology Department, Dentistry School, USP, Sao Paulo-SP, Brazil. Technical procedures, manuscript \\ writing.

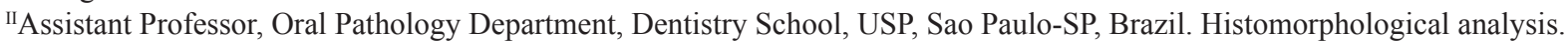 \\ IIIAssistant Professor, General Pathology Department, Dentistry School, USP, Sao Paulo-SP, Brazil. Images acquisition and interpretation of data, \\ statistical analysis.

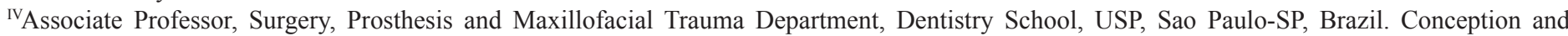 \\ scientific content of the study, supervision all phases, critical revision.
}

\begin{abstract}
PURPOSE: To analyze the effects of aqueous ozone irrigation over bone healing in hyperglycemia-induced rats.

METHODS: Forty-eight male Wistar rats were allocated into Group H (hyperglycemic) or Group N (control). Monocortical bone wound were performed on femurs' anterolateral face. Wounds were treated with a trans-operatory single irrigation of $100 \mathrm{ml}$ of aqueous ozone $[0.004 \mathrm{mg} / \mathrm{ml}]$ whereas control groups received $100 \mathrm{ml}$ of pure water (Milli-Q ${ }^{\circledR}$ ). Histomorphological and histomorphometrical analyses were accomplished after seven, 14 and 21 days. Kruskal-Wallis and Mann-Whitney statistical tests were applied for bone neoformation quantification and assessment.

RESULTS: Aqueous ozone wounds irrigated revealed diffuse hemorrhage and increased neoformed of blood vessels number. There was no statistical significant difference in bone trabeculae neoformation. After seven and 14 days, the number of osteoclasts was higher in aqueous ozone groups than in those treated with pure water.

CONCLUSION: Independently of blood glucose levels, aqueous ozone allowed an increase in blood vessels neoformation and osteoclast migration, without affect bone trabeculae neoformation.
\end{abstract}

Key words: Bone. Ozone. Osteoclasts. Hyperglycemia. Rats. 


\section{Introduction}

Bone healing comprises coordinated interaction between different cells types and release of several cytokines ${ }^{1}$. Oxygen plays a pivotal role in tissue repair, mainly regarding local angiogenesis improvement and stimuli of undifferentiated cell migration ${ }^{2}$.

Hyperglycemia leads to osteopenia and impairment of wound healing, which is intimately associated with unbalance between the production and the metabolism of reactive oxygen species $(\mathrm{ROS})^{3}$.Also, hyperglycemia can increase the inflammatory response and the osteoclastic activity, which can compromise the bone neoformation during bone repair $^{4,5}$.

Ozone is toxic to the respiratory system but recently has been reported to be safe for a variety of medical and dental treatments ${ }^{6}$. Literature describes that its dilution in water (aqueousozone) or ozonized-oil produces a securer and more stable vehicle when compared to gaseous ozone ${ }^{7}$. Recently some authors described the clinical use of ozonized water as an alternative management strategy for periodontitis ${ }^{8}$. The use of ozonized-oil for the treatment of bisphosphonate related jaws osteonecrosis was also described with positive results ${ }^{9,10}$. However, there is a lack of in vivo studies in animal models to certificate the exact cellular pathways which ozone interacts with mineralized tissues and which are the safe doses for its applications.

The aim of the study was to analyze the effects of aqueous ozone irrigation on bone trabeculae neoformation and osteoclasts number in standard monocortical femoral wound of hyperglycemia-induced rats.

\section{Methods}

This research was conducted at the Animal Experimentation Laboratory of the Oral Surgery Department of School of Dentistry of the University. All the procedures were approved by the institutional Committee of Experimental Animal Research under protocol number 04/2009 and followed the recommendations of the Brazilian Society of Laboratory Animal Science (SBCAL- COBEA).

Forty-eight male rats (Rattus norvegicus Albinus, Wistar) weighing from $200 \mathrm{~g}$ to $250 \mathrm{~g}$ were kept in natural ventilated polypropylene cages lined with sterile wood shavings, under day/night cycle of 12/12 hours with food and water ad libitum. The animals suffered standard bone wounds and were distributed randomly into two groups: Group $\mathrm{H}$ (hyperglycemic) and Group N (control). Both groups were subdivided into "water" and "ozone" in accordance with the treatments of the wounds (see below).

\section{Hyperglycemia induction}

Twenty-four animals (Group H) were rented to hyperglycemia by a single intraperitoneal dose of Streptozotocin (STZ - Sigma Chemical Co. St Louis, MO, USA) (60mg/kg) using solution of sodium citrate buffer as vehicle $(0.1 \mathrm{~mL})$. The animals of the control group (Group N) were treated with the vehicle alone. Capillary blood glucose of all animals was checked seventytwo hours after drug administration and immediately before the surgical procedures by a monitor (Accucheck - Roche ${ }^{\circledR}$ ) using a blood drop from a tail tip wound. Animals showing blood glucose levels above $110 \mathrm{mg} / \mathrm{dL}$ were considered hyperglycemic.

\section{Ozonized water production}

Ozone was produced from pure oxygen as a direct result of an electrical discharge employing an ozone generator (Ozone \& Life Model O\&L3.0RD). Oxygen flow rate adjusted to $1 / 2 \mathrm{~L} /$ min and ozone at $41 \mathrm{mg} / \mathrm{L}$ of ozone/oxygen gaseous concentration was bubbled in $2000 \mathrm{mlMilliQ}{ }^{\circledR}$ water freshly prepared. Water ozonization was performed for $5 \mathrm{~min}$ to obtain a final concentration of ozonized water of $0,004 \mathrm{mg} / \mathrm{ml}$. A filter shattered ozone residual gas from the scrubber. Concentration of diluted ozone in water was checked during the experiment by the Indigo Blue method using Ozone-Chemets Kit (Chemetrics; Calverton, VA, USA).

\section{Surgical procedures}

Prophylactic antibiotic therapy was performed in all groups with benzyl penicillin $G$ benzathine (Roche $\left.{ }^{\circledR}\right), 150.000$ $\mathrm{UI} / \mathrm{Kg}$ intramuscularly. General anesthesia was achieved by intramuscular injection of hydrochloride ketamine (Dopalen ${ }^{\circledR}$ Vetbrands) and xylazine (Rompum ${ }^{\circledR}$ - Bayer SA) a dose of $0.8 \mathrm{mg} /$ $\mathrm{kg}$ and $0.3 \mathrm{mg} / \mathrm{kg}$, respectively.

Antero lateral femurs faces were accessed through an incision of the skin and resection of soft tissues. Monocortical bone defects were created using trephine burs with $2 \mathrm{~mm}$ of diameter $\left(\right.$ Dentoflex $^{\circledR}$ ). Bone perforations were irrigated with $100 \mathrm{~mL}$ of aqueous ozone in animals of Group $\mathrm{N}_{\text {ozone }}(\mathrm{n}=12)$ and animals of Group $\mathrm{N}_{\text {ozone }}(\mathrm{n}=12)$. Bone perforations of the twelve animals of Group $\mathrm{H}_{\text {water }}$ and Group $\mathrm{N}_{\text {water }}$ underwent irrigations with $100 \mathrm{ml}$ MilliQ ${ }^{\circledR}$ water only. The internal soft tissues were repositioned and sutured (silk thread 3.0-Ethicom, Johnson \& Johnson ${ }^{\circledR}$ ). Skin was realigned and also sutured (Nylon 3.0-Brasuture ${ }^{\circledR}$ ).

At seven, 14 and 21 days postoperatively four animals, in each group, were euthanatized in a $\mathrm{CO}_{2}$ chamber. 


\section{Histomorphological and histomorphometric analysis}

The femurs were dissected and kept in 10\% formaldehyde for 48 hours before decalcification in 10\% EDTA ( $\mathrm{pH} 7.4$ ) for six weeks. The femurs were cut lengthy and embedded in paraffin. Some representative fragments of pancreas in the group $\mathrm{H}$ were also collected for $\beta$-cells analysis in the Langerhans islet. Histological sections with $5 \mu \mathrm{m}$ were stained with hematoxylin and eosin (H\&E).

Two blind trained observers accomplished the histomorphological analyses. An arbitrary scale was applied to describe healing features (rates: $0=$ absent, $1=$ discrete, 2 $=$ moderate, 3 = intense) in the site of the injury. Observers considered the presence of inflammatory infiltrate, edema, necrosis, and diffuse hemorrhage, presence of neoformed vessels and bone trabeculae, and hematopoietic bone marrow.

\section{Bone trabeculae neoformation}

For bone trabeculae analysis, two sections of each wound (four fields at 100x original magnification in each section) were analyzed. Digital images of each field were obtained using a CCD camera $\left(\right.$ Sony ${ }^{\circledR}$, Tokyo, Japan) and the percentage of bone trabeculae area was calculated by means RGB subtraction using the histomorphometrical measurement software ImageLab2000 ${ }^{\circledR}$, Sao Paulo, Brazil.

\section{Osteoclast counting}

Osteoclast activity was determined through counting of osteoclastic cell line stained by Tartrate-resistant acid phosphatase (TRAP -Sigma-Aldrich, Saint Louis, MO, USA). For TRAP reaction, sections were deparaffinized, rinsed in $\mathrm{PBS}$ and incubated with a solution containing $50 \mathrm{mM}$ sodium acetate $(\mathrm{pH}$ 5.2), $0.15 \%$ naphthol-AS-TR- phosphate, $50 \mathrm{mM}$ sodium tartrate, and $0.1 \%$ Fast Red T.R (Sigma-Aldrich, kit \#387) for up to $2 \mathrm{~h}$ in water bath a $37^{\circ} \mathrm{C}$. Subsequently, the sections were rinsed in PBS and counterstained with Gill's hematoxylin for 1 minute at room temperature. Human blood smear was used as positive control. Specimens stained without sodium tartrate were considered as negative controls. Multinucleated giant cells TRAP-positive present in the callus region were manually counted in eight (8) fields at X400 magnification.

\section{Statistical analysis}

Histomorphological results were expressed in median and minimum/maximum values, and the data of bone trabeculae neoformation and osteoclast counting were in average and standard deviation. For histomorphometric analyses of non-parametric data, Kruskal-Wallis test was applied to the groups concomitantly, and Mann-Whitney test was for the pair of groups. Statistics were performed using Statistical Package for Social Sciences (SPSS, 17.0). The adopted significance level was 5\% (0.05).

\section{Results}

It could not be verified either signs of infection or femoral fracture in any of the animals used in this study. Table 1 shows the averages capillary blood glucose observed in the groups at the moment of surgical procedure. Body weight gain was significantly lower in Group H in all studied periods $(\mathrm{p}=0.0290)$.

TABLE 1 - Mean ( \pm standard deviation) values of capillary blood glucose at time of surgical procedure and of body weight gain at the end of experiment for each group.

\begin{tabular}{lcc}
\hline Variables & $\begin{array}{c}\text { Capillary blood } \\
\text { glucose }(\mathbf{m g} / \mathbf{d L})\end{array}$ & $\begin{array}{c}\text { Body weight gain } \\
(\%)\end{array}$ \\
\hline $\mathrm{N}_{\text {water }}$ & $84.00( \pm 4.56)$ & $102.47 \pm 3.46$ \\
$\mathrm{~N}_{\text {ozone }}$ & $84.25( \pm 2.13)$ & $131.62 \pm 3.32$ \\
$\mathrm{H}_{\text {water }}$ & $440.67( \pm 45.55)$ & $93.37 \pm 6.20$ \\
$\mathrm{H}_{\text {ozone }}$ & $446.83( \pm 23.29)$ & $99.90 \pm 4.26$ \\
$\mathrm{P}$ value & 0.0373 & 0.0290 \\
\hline
\end{tabular}

Kruskal-Wallis test. Significant when $\mathrm{p}<0.05$.

\section{Histomorphological and histomorphometric analysis}

Pancreas fragments exhibited moderate to intense necrosis in the Langerhans islets, confirming the toxic effect of streptozotocin in the group H. Table 2 shows the median values of intensity for some tissue components observed in the different experimental periods. In general, at seven days the group $\mathrm{N}_{\text {ozone }}$ exhibited more pronounced inflammatory infiltrate, edema, and vessel neoformation than $\mathrm{N}_{\text {water }}$ (Figure $1 \mathrm{~A}$ and C). Regarding hyperglycemic groups, $\mathrm{N}_{\text {ozone }}$ also showed more intense vessel neoformation than $\mathrm{H}_{\text {water }}$ (Figure $1 \mathrm{~B}$ and D). At 14 days, the groups $\mathrm{N}_{\text {ozone }}$ and $\mathrm{H}_{\mathrm{Ozone}}$ continue to exhibit more intense edema and higher number of vessels than $\mathrm{N}_{\text {water }}$ and $\mathrm{H}_{\text {water. Diffuse }}$ hemorrhage in the groups with ozone also was more pronounced, mainly in the $\mathrm{H}_{\text {ozone }}$ (Figure 2). Edema remains present in all the groups at 21 days, but they were more intense in $\mathrm{N}_{\text {ozone }}$ in the comparison with $\mathrm{N}_{\text {water }}$. Also vessel neoformation remains more intense in $\mathrm{N}_{\text {ozone }}$ and $\mathrm{H}_{\mathrm{Ozone}}$. These groups ( $\mathrm{N}$ and $\mathrm{H}$ ozone) exhibited remnants of blood clot at 21 days. Hematopoietic bone marrow was present in all the specimens in all periods with minimal intensity differences (Figure 3). 
TABLE 2 - Median values of histomorphological analysis [Min-Max].

\begin{tabular}{|c|c|c|c|c|c|c|}
\hline Groups & $\mathbf{N}_{\text {water }}$ & & & $\mathbf{N}_{\text {ozone }}$ & & \\
\hline Period (days) & $7 \mathrm{D}$ & $14 \mathrm{D}$ & $21 \mathrm{D}$ & $7 \mathrm{D}$ & $14 \mathrm{D}$ & $21 \mathrm{D}$ \\
\hline Inflammatory infiltrate & $2[1-2]$ & $1[1-1]$ & $0[0-0]$ & $3[3-3]$ & $1[1-2]$ & $1[1-1]$ \\
\hline Necrosis & $0[0-0]$ & $0[0-0]$ & $0[0-0]$ & $0[0-0]$ & $0[0-0]$ & $0[0-0]$ \\
\hline Blood clot & $2[2-3]$ & $2[1-2]$ & $0[0-0]$ & $2[2-2]$ & $2[1-2]$ & $1[1-1]$ \\
\hline Edema & $2[1-3]$ & $1[1-1]$ & $1[1-1]$ & $3[3-3]$ & $2[1-2]$ & $2[1-2]$ \\
\hline Vessels presence & $2[2-2]$ & $2[2-2]$ & $1[1-1]$ & $3[2-3]$ & $3[3-3]$ & $2[1-2]$ \\
\hline Hematopoietic tissue regeneration & $2[2-2]$ & $2[2-3]$ & $3[2-3]$ & $2[2-2]$ & $2[2-2]$ & $3[3-3]$ \\
\hline Groups & $\mathbf{H}_{\text {water }}$ & & & $\mathbf{H}_{\text {ozone }}$ & & \\
\hline Period(days) & $7 \mathrm{D}$ & $14 \mathrm{D}$ & $21 \mathrm{D}$ & $7 \mathrm{D}$ & $14 \mathrm{D}$ & $21 \mathrm{D}$ \\
\hline Inflammatory infiltrate & $1[0-2]$ & $2(1-2)$ & $2(1-2)$ & $1(0-1)$ & $2(1-2)$ & $2(1-2)$ \\
\hline Necrosis & $0[0-0]$ & $0(0-0)$ & $0(0-0)$ & $0(0-0)$ & $0(0-0)$ & $0(0-0)$ \\
\hline Blood clot & $2[2-3]$ & $2(1-2)$ & $1(1-1)$ & $2(2-2)$ & $3(2-3)$ & $2(1-2)$ \\
\hline Edema & $3[3-3)$ & $2(1-2)$ & $2(1-2)$ & $3(3-3)$ & $3(2-3)$ & $2(1-2)$ \\
\hline Vessels presence & $2[2-2)$ & $2(2-2)$ & $1(1-1)$ & $3(3-3)$ & $3(2-3)$ & $2(2-2)$ \\
\hline Hematopoietic tissue regeneration & $1[1-2)$ & $2(1-2)$ & $2(2-2)$ & $2(1-2)$ & $3(2-3)$ & $3(2-3)$ \\
\hline
\end{tabular}

$0=$ absent $; 1=$ discrete $; 2=$ moderate $;=$ intense.
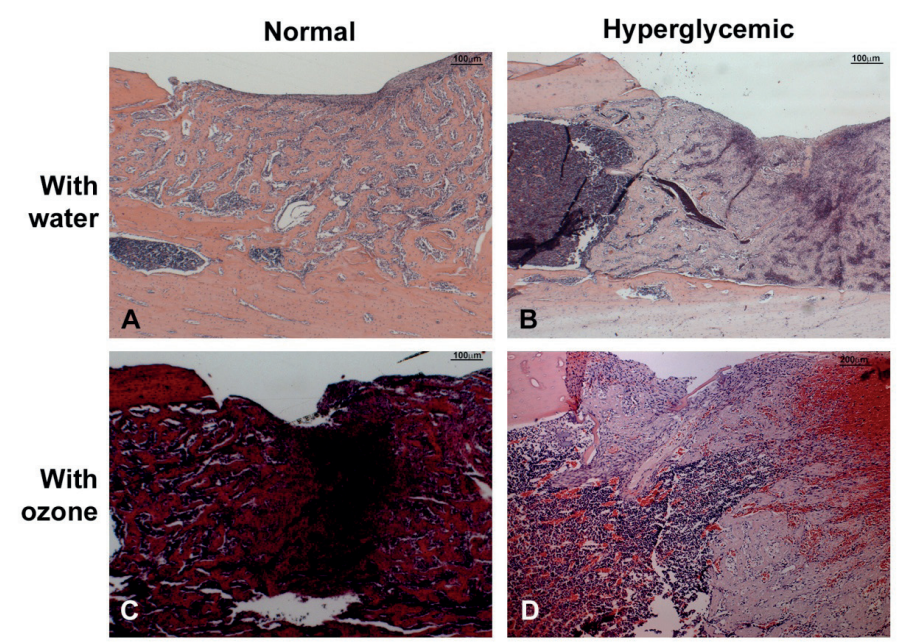

FIGURE 1 - Histological pattern of the bone defect at seven days (HE, original magnification 100x [A, B and C) and 200x (D)]. In the hyperglycemic individuals, mainly those treated with ozone (D), the granulation tissue is more exuberant with intense neovascularization than in the normal individuals. Normal individuals treated with ozone $(\mathbf{C})$ also show more angiogenesis than those treated with water (A).

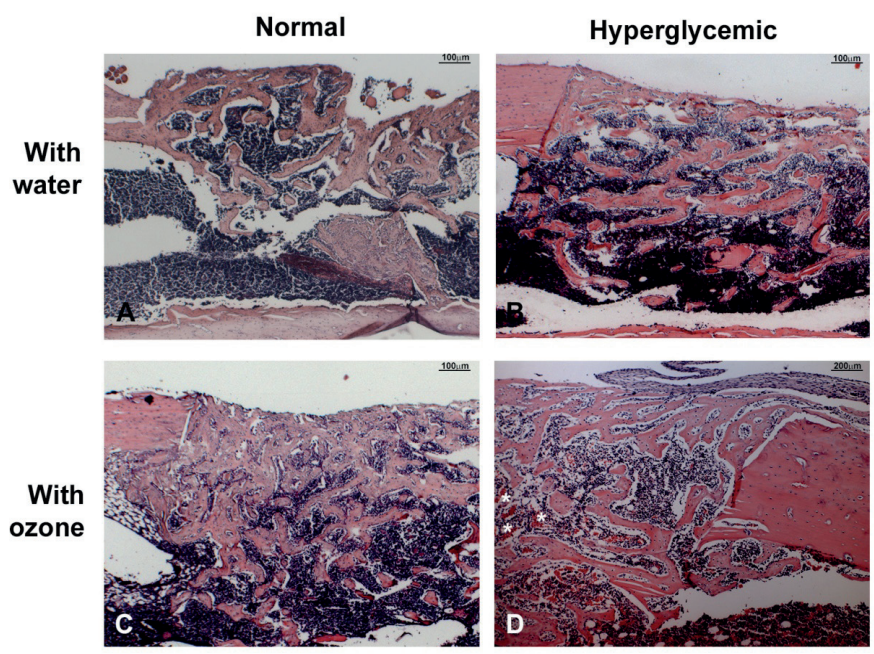

FIGURE 2 - Histological pattern of the bone defect at 14 days [HE, original magnification 100x (A, B and C) and 200x (D)]. Blood clot was partially substituted by new-formed bone in all the groups. However in the hyperglycemic group treated with ozone (D) remnants of the clot are more pronounced. In the normal individuals treated with ozone $(\mathbf{C})$, the bone trabeculae are more coalescent which may indicate that bone remodeling is more advanced in this group. 


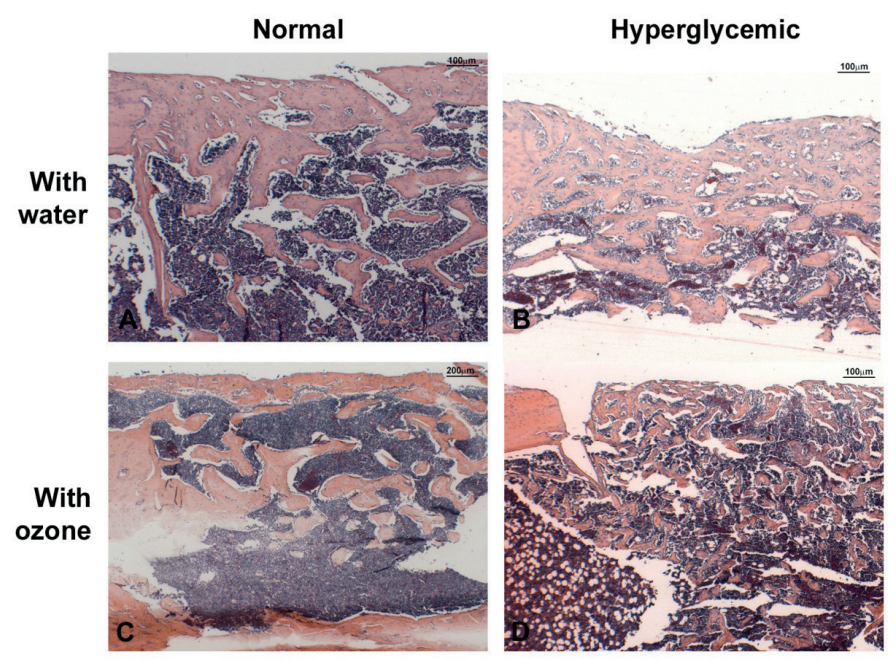

FIGURE 3 - Histological pattern of the bone defect at 21 days [HE, original magnification 100x (A, B and D) and 200x (C)]. Bone defect was completely fulfilled with new-formed bone trabeculae in all the groups. In the new-formed bone the hematopoietic marrow is exuberant in all the groups. In the normal individuals treated with water the new-formed trabeculae exhibited coalescent pattern and advanced remodeling.

The mean percentages of neoformed bone trabeculae for each group are presented in Figure 4. At seven days, the lowest mean percentage of neoformed bone was in the $\mathrm{N}_{\text {ozone }}$, but there were no statistically significant differences among the groups. At 14 days, the $\mathrm{N}_{\text {ozone }}$ showed the highest mean percentage of neoformed bone, but also there were no statistically significant differences among the groups. At 21 days, the highest mean percentage of neoformed was in the $\mathrm{N}_{\text {water }}$, but the differences were not significant.

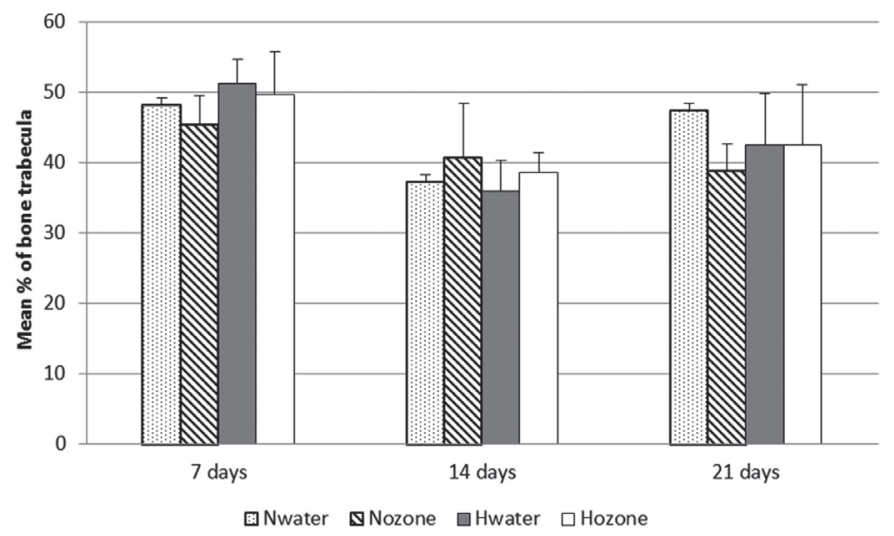

FIGURE 4 - Mean percentage of neoformed bone trabeculae in accordance with the experimental groups and periods $\left(\mathrm{N}_{\text {water }}-\right.$ normal group treated with water; $\mathrm{N}_{\text {ozone }}$ - normal group treated with ozone; $\mathrm{H}_{\text {water }}$ - hyperglycemic group treated with water; $\mathrm{H}_{\text {ozone }}$ - hyperglycemic group treated with ozone).

\section{Osteoclast counting}

Figure 5 shows TRAP-positive cells which present morphology of osteoclasts. These cells were adjacent to the newformed trabeculae in the region of the surgical defect. In some fields it was possible to observe these cells in the Howship lacunae, which may indicate active bone resorption. The mean number of osteoclasts is depicted in Figure 6. $\mathrm{N}_{\text {ozone }}$ exhibited the highest number of osteoclasts at seven and 14 days, with significant difference in the comparison with the other groups $(\mathrm{p}<0.05)$. At 21 days the highest number was for group $\mathrm{H}_{\mathrm{Ozone}}$, but without significant differences.
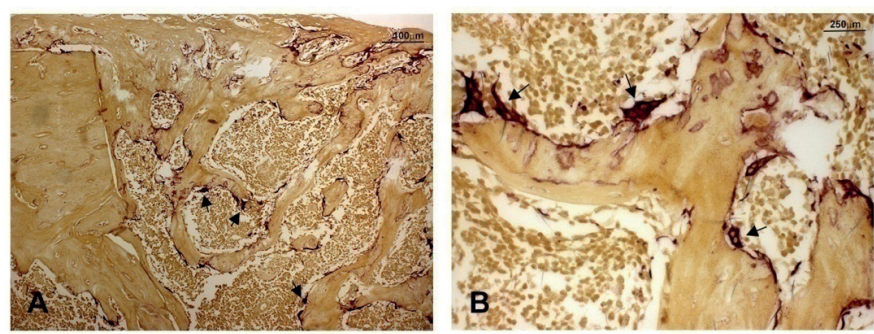

FIGURE 5 - Example of TRAP-positive cells in the bone defect $(*)$ of normal individuals treated with ozone [Tartrate-resistant acid phosphatase, 100x (A) and 400x (B)]. Positive cells are multinucleated and are adjacent to the new-formed bone, being compatible with osteoclasts (arrows).

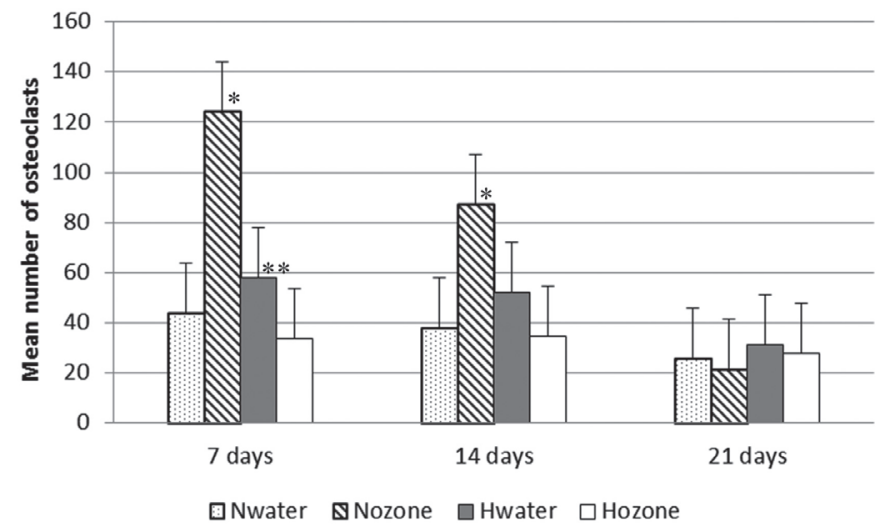

FIGURE 6 - Mean number of osteoclasts in accordance with the experimental groups and periods $\left(\mathrm{N}_{\text {water }}\right.$ - normal group treated with water; $\mathrm{N}_{\text {ozone }}$ - normal group treated with ozone; $\mathrm{H}_{\text {water }}$ - hyperglycemic group treated with water; $\mathrm{H}_{\mathrm{ozone}}$ - hyperglycemic group treated with ozone). * Statistically significant when compared with other groups $(\mathrm{p}<0.05)$. ** Statistically significant when compared with $\mathrm{H}_{\text {ozone }}(\mathrm{p}<0.05)$.

\section{Discussion}

The histomorphological evaluations revealed that aqueous ozone might affect bone repair by enhancing vascular neoformation and extending osteoclast number near healing region, but was not able to stimulate bone trabeculae neoformation. Previous investigations reported that ozone interactions with 
organic fluids stimulates vascular neoformation through a ROS mediates mechanism ${ }^{11}$ and improves inflammatory response within pro-inflammatory cytokines interleukin-1 (IL-1) and factor- $\alpha$ tumor necrosis (TNF- $\alpha$ ) release ${ }^{12}$.

The tartrate-resistant acid phosphatase (TRAP) staining revealed significant augment of osteoclasts counting nearby the majority of all defects submitted to aqueous ozone irrigation after seven and fourteen days. One of the regulatory mechanisms of osteoclast activity is reactive oxygen species (ROS) $)^{13,14}$. Therefore, we can assume that aqueous ozone boosted ROS concentrations and that it may have stimulated osteoclast migration near the wound.

Ozone toxicity for respiratory tissues is widely known. However, due to its high instability, different vehicles have been engaged for ozone delivery ${ }^{6,15}$. Managing of water or oil as vehicle has been described to be safe and convenient. In this research $41 \mathrm{mg} / \mathrm{L}$ of ozone/oxygen dilution in $2 \mathrm{~L}$ MilliQ water was employed to irrigate bone wounds. At this concentration, no harmful effects to bone healing could be seen. This concentration of aqueous ozone $(0,004 \mathrm{mg} / \mathrm{ml})$ was based on other studies that established in vitro antibacterial activity for similar concentrations $(0,002-0,004 \mathrm{mg} / \mathrm{ml})^{16,17}$.

In this study, all the animals submitted to STZ injection achieved high blood glucose levels and pancreatic islets exhibited necrosis. Although wound healing could be considered satisfactory in all the hyperglycemic animals, there was a noteworthy substitution of bone marrow by fat tissue, indicating chronic hyperglycemia. The employment of streptozotocin to induce hyperglycemia in animals represents the most common experimental to simulate diabetes ${ }^{18}$.

No defective healing of $2 \mathrm{~mm}$ bone defects could be associated to hyperglycemia after 21 days. Bone defect size was based in Follak et al. ${ }^{19}$ study of the diabetic influence in the bone healing of different defect sizes in diabetic rats poorly and well compensated.

Among study limitations we could recognize the short sample and the histomorphometric analysis inherent variations. Both of them may have added to apparently uneven scores. In further studies, it would be of particular interest to consider if different aqueous ozone concentration shows a dose-response curve in trabeculae count. Prolonged dose administration could trigger mechanisms of cell interactions that could explain the successful clinical results that literature has shown.

Although the methodology employed in this research was not able to completely show the ozone ability to improve tissue repair process in a hypoxic and highly oxidative stressed environment, as seen in diabetes mellitus. In further studies, it would be of particular interest to investigate different aqueous ozone concentration and prolonged dose administration in triggering mechanisms of cell interactions that could explain the successful results that literature has shown. A better understanding of the real role of oxygen-ozone molecules over angiogenesis, osteoclasts and bone trabeculae repair will eventually result in the development of clinically efficient therapies.

\section{Conclusion}

Independently of blood glucose levels, aqueous ozone irrigation of Wistar rats' standard femoral wounds improved capillary neoformation and enhanced osteoclast migration in wound healing regions without interference in bone trabeculae neoformation.

\section{References}

1. Samee M, Kasugai S, Kondo H, Ohya K, Shimokawa H, Kuroda S. Bone morphogenetic protein-2 (BMP-2) and vascular endothelial growth factor (VEGF) transfection to human periosteal cells enhances osteoblast differentiation and bone formation. J Pharmacol Sci. 2008;108:18-31.

2. Wang Y, Wan C, Deng L, Liu X, Cao X, Gilbert SR, Bouxsein ML, Faugere MC, Guldberg RE, Gerstenfeld LC, Haase VH, Johnson RS, Schipani E, Clemens TL. The hypoxia-inducible factor alpha pathway couples angiogenesis to osteogenesis during skeletal development. J Clin Invest. 2007;117:1616-26.

3. Thrailkill KM, Lumpkin CK Jr, Bunn RC, Kemp SF, Fowlkes JL. Is insulin an anabolic agent in bone? Dissecting the diabetic bone for clues. Am J Physiol Endocrinol Metab. 2005;289:E735-45.

4. Kayal RA, Alblowi J, McKenzie E, Krothapalli N, Silkman L, Gerstenfeld L, Einhorn TA, Graves DT. Diabetes causes the accelerated loss of cartilage during fracture repair which is reversed by insulin treatment. Bone. 2009;44:357-63.

5. Liu R, Bal HS, Desta T, Krothapalli N, Alyassi M, Luan Q, Graves DT. Diabetes enhances periodontal bone loss through enhanced resorption and diminished bone formation. J Dent Res. 2006;85:5104.

6. Bocci V. Is it true that ozone is always toxic? The end of a dogma. Toxicol Appl Pharmacol. 2006;216:493-504.

7. Bocci VA. Why orthodox medicine has not yet taken advantage of ozone therapy. Arch Med Res. 2008;39:259-60.

8. Kshitish D, Laxman VK. The use of ozonated water and $0.2 \%$ chlorhexidine in the treatment of periodontitis patients: a clinical and microbiologic study. Indian J Dent Res. 2010;21:341-8.

9. Agrillo A, Petrucci MT, Tedaldi M, Mustazza MC, Marino SM, Gallucci C, Iannetti G. New therapeutic protocol in the treatment of avascular necrosis of the jaws. J Craniofac Surg. 2006;17:1080-3.

10. Ripamonti CI, Cislaghi E, Mariani L, Maniezzo M. Efficacy and safety of medical ozone (O3) delivered in oil suspension applications for the treatment of osteonecrosis of the jaw in patients with bone metastases treated with bisphosphonates: Preliminary results of a phase I-II study. Oral Oncol. 2011;47:185-90.

11. Sagai M, Bocci V. Mechanisms of Action Involved in Ozone 
Therapy: Is healing induced via a mild oxidative stress? Med Gas Res. 2011;1:29.

12. Kim HS, Noh S, Han YW, Kim KM, Kang H, Kim HO, Park YM. Therapeutic effects of topical application of ozone on acute cutaneous wound healing. J Korean Med Sci. 2009;24:368-74.

13. Reddy SV. Regulatory mechanisms operative in osteoclasts. Crit Rev Eukaryot Gene Expr. 2004;14(4):255-70.

14. Luvizuto ER, Dias SS, Okamoto T, Dornelles RC, Okamoto R. Raloxifene therapy inhibits osteoclastogenesis during the alveolar healing process in rats. Arch Oral Biol. 2011;56(10):984-90.

15. Millar BJ, Hodson N. Assessment of the safety of two ozone delivery devices. J Dent. 2007;35(3):195-200.

16. Nagayoshi M, Fukuizumi T, Kitamura C, Yano J, Terashita M, Nishihara T. Efficacy of ozone on survival and permeability of oral microorganisms. Oral Microbiol Immunol. 2004;19:240-6.

17. Cardoso MGC, Oliveira LD, Koga-Ito CY, Jorge AOC. Effectiveness of ozonated water on Candida Albicans, Enterococcus faecalis and endotoxins in root canals. Oral Surg Oral Med Oral Pathol Oral Radiol Endod 2008;105:e85-91.

18. Kayal RA, Alblowi J, McKenzie E, Krothapalli N, Silkman L, Gerstenfeld L, Einhorn TA, Graves DT. Diabetes causes the accelerated loss of cartilage during fracture repair which is reversed by insulin treatment. Bone. 2009;44(2):357-63.

19. Follak N, Klöting I, Wolf E, Merk H. Histomorphometric evaluation of the influence of the diabetic metabolic state on bone defect healing depending on the defect size in spontaneously diabetic BB/ OK rats. Bone. 2004;35(1):144-52.

\section{Acknowledgment}

To Professor Willfredo Urruchi (PhD) for technical assistance.

\section{Correspondence:}

Maria Cristina Zindel Deboni

Faculdade de Odontologia da USP

Departamento de Cirurgia, Prótese e Traumatologia Bucomaxilofaciais Avenida Professor Lineu Prestes, 2227

05508-000 São Paulo - SP Brasil

Tel.: (55 11)3091-7832

mczdebon@usp.br

Received: January 13, 2013

Review: March 17, 2013

Accepted: April 14, 2013

Conflict of interest: none

Financial source: Coordination of Improvement for Higher Academic Staff (CAPES)

${ }^{1}$ Research performed at Division of Oral Surgery, Department of Surgery, Prosthesis and Traumatology Maxillofacial, School of Dentistry, University of Sao Paulo (USP), Brazil. Part of Master degree thesis, Dental Sciences, Oral and Maxillofacial Surgery and Traumatology. Tutor: Prof. Dra. Maria Cristina Zindel Deboni. 